\title{
COVID-19's Impact on Chinese Tourism Industry
}

\author{
Shirley Wang 1 , a \\ ${ }^{1}$ Shen Wai International School, SWIS, Shenzhen, China \\ a22.Shirley.Wang@swis.cn
}

\begin{abstract}
This paper covers the impact and trend of COVID-19 on Chinese tourism industry, specifically about tourist attraction, tour company, and accommodation. The whole tourism industry is facing a huge loss, and expectedly it can fully recover at the end of the third quarter. Chinese governments set up the tourism support policies to help with those companies, and many of them have already taken actions to provide things online to save their loss of income.
\end{abstract}

Keywords: Tourism industry, Coronavirus, Impact.

\section{Introduction}

The novel coronavirus pandemic known as COVID-19 has spread globally since the beginning of 2020, which has dramatically affected human lives as people spending most of their time at home quarantine and enduring social distancing. In addition to human beings, the worldwide economy has been tremendously influenced by the virus as well. A broad variety of industries, especially the tourism industry, have shut down and caused unemployment. Some countries that rely on tourism, such as the Maldives (38.92\% of GDP) and the British Virgin Islands (32.96\% of GDP), are facing serious challenges. (Frost, 2019) This paper explains the impacts the coronavirus has on the tourism industry in China, specifically tour companies, tourist attractions, and accommodation, and introduces some methods to address the issue.

Tourism is defined as temporary movements individuals make to transit to areas other than where they commonly dwell for leisure purposes, according to Revfine. It is one of the biggest industries worldwide and mainly involves the catering industry, hospitality industry, transportation, and entertainment. Tourism is a huge sector of the world's economy and has increased the number of values to the global GDP in the past ten years. In 2019, tourism comprised 9.3 trillion US dollars (6.7 percent) of global GDP. China, as the second greatest contributor globally, its tourism made a notable contribution of 10.94 trillion yuan to the country's GDP (11.05\%) in 2019.

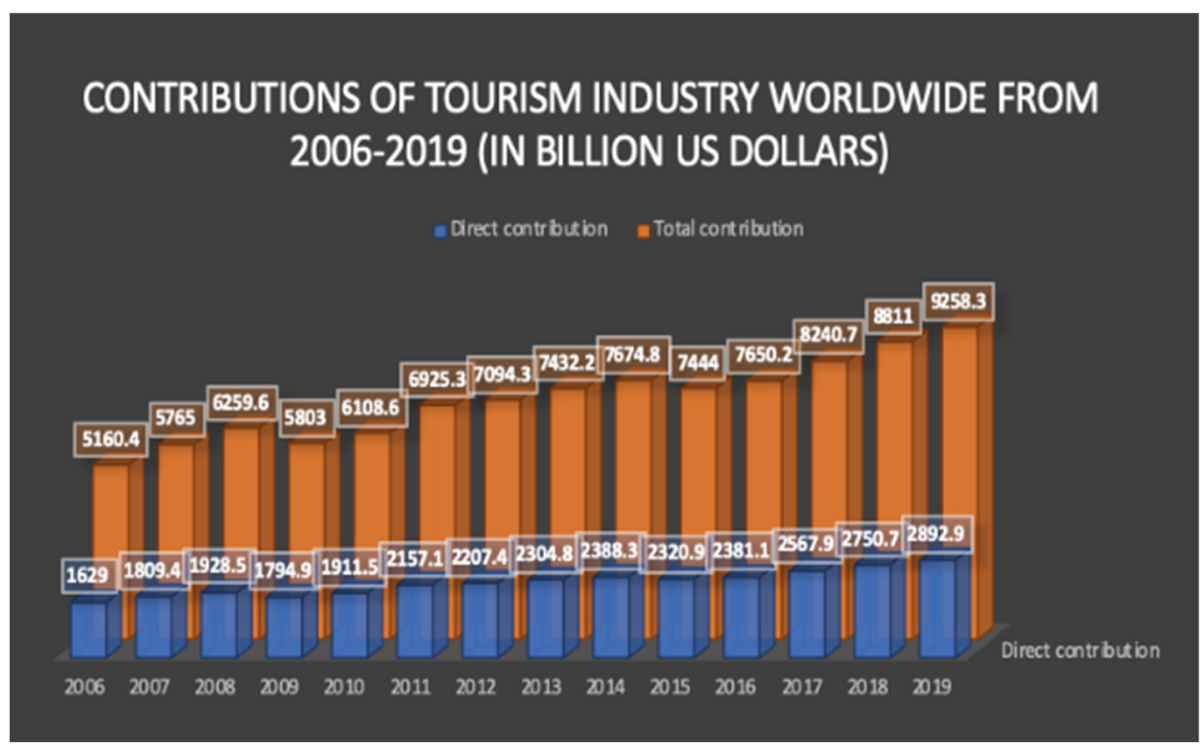

Figure 1. Contributions of tourism industry worldwide from 2006-2019

Source: Statista

\section{Organization of the Text}

\subsection{Tourist Attraction}

\subsubsection{Tourist Attractions in Different Areas Have Shut} Down, and Companies Have Huge Losses

In recent years, more and more people choose to travel in their leisure time, causing the Chinese tourism industry to flourish. During the coronavirus pandemic, the income of tourist attractions is affected significantly because all of them had shut down, and the number of tourists declined due to the cancellation of transportation. The pandemic not only affected tourist attractions in the whole country but also affected them severely in the long run. During the Spring Festival, the income loss of tourist attractions in China 
reached more than $90 \%$ of the same period last year. The annual income loss is expected to reach $40 \%-50 \%$ of the previous year.

China Tourist Attractions Association has investigated the loss of tourist attractions in different regions. In Guangdong province, 385 out of 423 tourist attractions had shut down, another 23 partially closed, and the rest of 15 still open. According to the survey, the cumulative net investment of tourist attractions company in Guangdong Province during the Spring Festival exceeded 230 million yuan, excluding public welfare tourist attractions, and the average net investment per tourist attraction was 720,000 yuan. Before and after the Spring Festival holiday alone, the cumulative losses of the tourist attraction company in Guangdong reached 586 million yuan. Excluding public welfare tourist attractions, the average loss per tourist attraction was 1.76 million yuan.

In Xinjiang Autonomous Region, $52 \%$ of the tourist attractions (83 in total) lost 100\% of their revenue in the first quarter, and $71 \%$ of the tourist attractions lost more than $60 \%$ of their revenue. Looking through the whole year, $42 \%$ of the tourist attractions are expected to lose more than $50 \%$ of their annual income, and $67 \%$ of them may lose more than $30 \%$. In Yunnan Province, 99\% of the tourist attractions (165 in total) currently have no business and no income. The average reception of tourist attractions in Yunnan Province during the Spring Festival decreased from 54,800 in 2019 to 37,700, a decrease of $93 \%$, and the loss of income during the Spring Festival decreased by $71 \%$ comparing to the same period last year. Not only the revenue of tourist attractions in the first quarter dropped sharply, but also the annual income will lose a lot. At the same time, tourist attractions also face problems such as large fixed cost expenditures and large financial expense expenditures.

In Hunan Province, the average loss of revenue for each tourist attraction caused by tourists canceling orders was 3.68 million yuan. In the first quarter, the average revenue of each tourist attraction enterprise decreased by 5.74 million yuan compared to the first quarter last year. According to the statistical analysis, in Shanghai, the average income loss of 148 tourist attractions during the Spring Festival is about 2.16 million yuan. In Hebei Province, according to the investigation, the impact of the pandemic on Yesanpo Scenic Spot is expected to continue into the first half of the year, and the ticket revenue of the scenic spot is expected to decrease by 50 million yuan. Baishi Mountain lost 17 million yuan from January to March, of which the engineering and marketing investment in the early Spring Festival totals 800,000 yuan, and the labor cost was 4.5 million yuan. East Taihang Mountain predicts the income loss will reach 31 million yuan from January to May, including labor costs of 3.4 million yuan and bank loans Interest of 5.46 million yuan. (NEW LVJIE, 2020)

Huangshan Tourism Development Corporation is a large tourism listed company in China. The company's chairman has recently been interviewed, and he said that the company lost 60 million yuan during the Spring Festival. Their annual revenue in recent years has been around 1.6 billion yuan, spreading to 4.5 million per day. As long as Huang Mountain is closed for one day, they will lose 4.5 million yuan. Therefore, obviously, many tourist attractions are facing huge losses brought by the cost of labor, no entrance ticket income, and some other costs. Huangshan Tourism Development Corporation's profit fell from more than 23 million yuan in the first quarter of 2019 to a loss of more than 77 million yuan in the first-quarter of this year. In the first quarter of 2020, operating income was 69.792 million yuan, a year-on-year decrease of $73.59 \%$; net profit loss was 77.241 million yuan, a year-on-year decline of $42.71 \%$. Huangshan Tourism Corporation's first quarter report for 2020 shows that the number of tourists entering the mountain fell by $81.15 \%$ in the first quarter.

However, with the improvement of the pandemic, the tourism industry will gradually recover. Since the end of February, many tourist attractions have started to reopen, and until the end of April, 94\% of tourist attractions have reopened. In the Labor Day holiday in May, the number of tourists in China exceeded 100 million.

\subsection{Tour Company}

\subsubsection{Revenues of Travel Agencies Have Dropped Significantly}

Affected by the pandemic, all the travel groups were canceled on January $27^{\text {th }}$ announced by the Chinese government. According to the China Association of Travel Services, 13525 travel groups have cancelled in Beijing, causing the number of tourists to decrease by 242 thousand. All the tour companies are facing a huge loss.

Yunnan Tourism Company has the largest decline in net profit among all the tour companies. It lost more than 25 million yuan in the first quarter. The net profit for the same period last year was 1.784 million yuan, a year-on-year decline of $1501.35 \%$ to $1781.61 \%$. According to the announcement, Yunnan Tourism Company suspended the tour of subordinate tourist attractions from January $25^{\text {th }}$, and the business of subordinate travel agencies, tourism transportation, conference wedding banquets, etc., was temporarily suspended. However, with the orderly resumption of production in the national scenic spots, some tourist attractions have reopened in March.

According to the investigation by China Tourism Research Institute, only $20.7 \%$ of people are willing to travel as soon as the pandemic is over. Thus, some tour companies are also worried about the hidden effect brings by the pandemic. First, tourism is not a necessary expenditure in the household consumption budget. The pandemic has brought an impact on the domestic economy, which has brought about changes in people's expectations of economic development, which in turn has led to a decline in consumer willingness to travel. Moreover, the global environment has changed. Judging from the current situation, inbound tourism and outbound tourism can hardly recover this year. Finally, it will take time for the tourism industry to recover fully. At this time, more and more people will not go to travel, and tourist attractions will be more cautious when opening. 


\section{Travel choice tendency of Chinese residents after the pandemic}

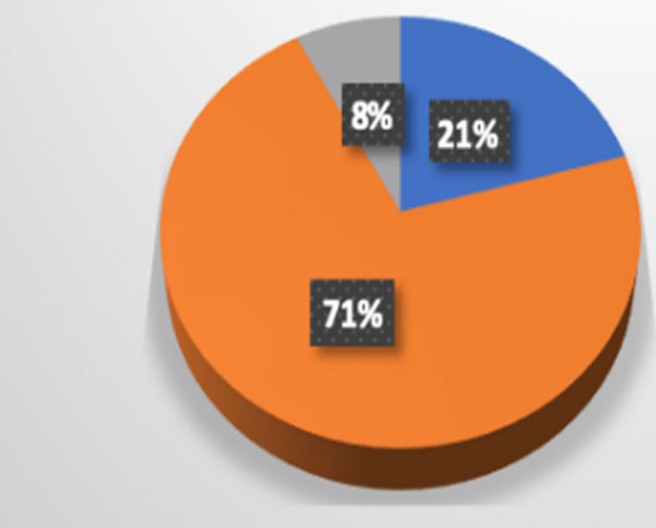

- Travel as soon as the pandemicis over

May to go travel after the pandemichas passed a while

nother

Figure 2. Travel choice tendency of Chinese people after the pandemic Source: China Tourism Research Institute

\subsection{Accommodation}

\subsubsection{Accommodation Has Become One of the Most Damaged Industries, and Occupancy Fell Significantly}

With the stagnation of transportation and tourism, the accommodation has been affected seriously. From January $14^{\text {th }}$ to January $26^{\text {th }}, 2020$, the average occupancy rate of hotels in Mainland China fell by $75 \%$ overall, according to

\section{STR.}

The occupancy rate of hotels in mainland China reached a pinnacle of $70 \%$ on January $14^{\text {th }}$, but then it gradually decreased. On January $26^{\text {th }}$, the occupancy rate fell to $17 \%$, which means that eight out of every ten rooms are empty. The average house price started to rise on the $19^{\text {th }}$ and reached a monthly peak of $754 \mathrm{RMB}$ on the $26^{\text {th }}$, increasing $61 \%$ compared with January $19^{\text {th }}$.

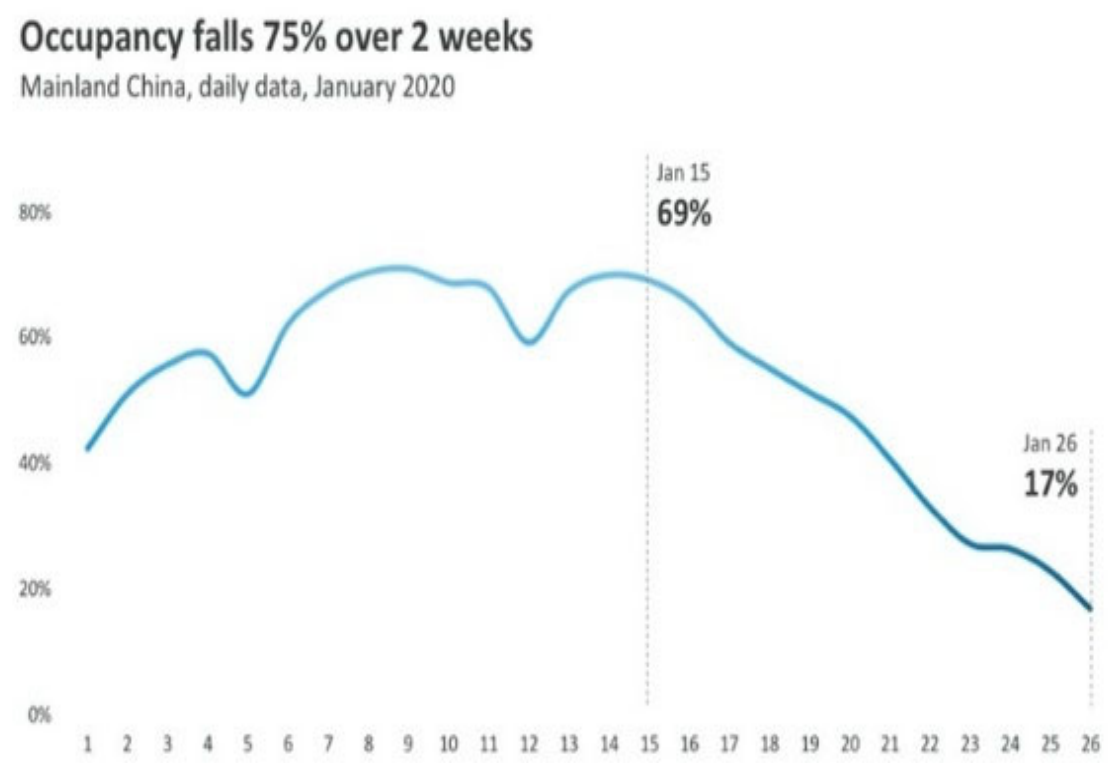

Figure 3. Occupancy rate of hotel in China in January

Source: STR

Since 2015, the average occupancy rate of hotels in mainland China during the Spring Festival has remained at around $55 \%$. However, from January $23^{\text {rd }}$ to $26^{\text {th }}$ this year, the occupancy rate has fallen to $22 \%$. Normally, the average house price will usually be in the range of $650-700 \mathrm{RMB}$, and the average house price for these four days this year has reached $711 \mathrm{RMB}$. Looking at the year-on-year change rate, preliminary data for 2020 show that the occupancy rate fell $71 \%$ year-on-year, but the average house price increased $10 \%$ year-on-year. (STR, 2020) 
On March $11^{\text {th }}$, China Hotel Association issued a report about the impact and trend of coronavirus pandemic on the Chinese accommodation industry. The report shows that the accommodation industry has become one of the most damaged industries due to the epidemic. In January and February, hotel companies lost more than 67 billion yuan, and expectedly normal operations will resume after six months. The investigation reveals that a large number of rooms, private rooms, banquets, conferences, annual meetings, and vacation plans that have been booked for the Spring Festival in January were unsubscribed. In February, the average revenue of mid-range hotels decreased by $86 \%$ year-on-year, reaching 4.95 million yuan each, and the average revenue of below-average hotels decreased by $92 \%$ year-on-year, approximately 720,000 yuan each. $74.29 \%$ of hotels chose to close their stores directly, with average closing days of 27 days.

As of the end of February, $63.3 \%$ of hotels have reopened, and the rate of employee resumption has reached $65 \%$. However, the region where inbound tourists gather will continue to be affected. If the accommodation industry fully recovers after six months, it is expected that the annual revenue will decline by $24 \%$ year-on-year.

\subsection{Solutions}

Considering the condition of SARs in 2003, the domestic tourism industry will fully recover at the end of the third quarter or fourth quarter, which still depends on the global condition. Until now, many industries and corporations have taken actions to reduce their loss of income. For tourist attraction companies, they can provide an online visit for customers and charge some entrance fees to make up for the loss. For example, Beijing Zoo has set up live broadcast and show its animals to tourist. Since the Zoo has been closed, the cost of feeding animals is a huge financial burden. Thus, the live broadcast provides a platform for tourists to see those animals at home and feed the animals online by paying for the food. Also, tourist attractions can limit the number of tourists who enter the area and ensure everyone is healthy. Like Huang Mountain, it only allows 15,000 people to enter the mountain per day.

For travel agencies, they can catch the chance to build an online platform and create some chance to interact with tourists to get attention. For example, Mafengwo developed "\#The most wanted place to go after the epidemic" wishing activity, and users can write the destination they want to travel on the page. In this case, they can seize business opportunities by looking through the discussion.

For the accommodation, hotels can induce AI technology into hotel and use robot to help guests check-in, check-out, and clean the rooms regularly to reduce contact between people. For instance, the FlyZoo Hotel in Hangzhou, established by Alibaba. They use cutting-edge tech to help transform the hospitality industry so guests can book their rooms, choose floors, and get their room's directions using the FlyZoo Hotel app. In the elevator, the guests can use facial recognition technology to enter the floor where their rooms are. Also, each room contains a Tmall Genie smart assistant, and guests can ask questions freely when they need helps. Moreover, hotels can build connections with food delivery platforms like Meituan to sell the food in their restaurant.

Chinese governments are also trying to support tourism. They give labor subsidies to companies in order to reduce their labor cost. They allow companies to delay tax payments and reduce property tax, rent, and energy fees.

\section{Summary}

The coronavirus has caused a huge loss on the Chinese tourism industry, especially in travel agencies, tour companies, and accommodation. The negative impact of COVID-19 will still go on until the fourth quarter of 2020 as the pandemic has been relatively controlled, but many solutions appeared to help those companies overcome the difficulties, and Chinese governments are actively taking actions to adjust policies to support them.

\section{Acknowledgment}

I would like to express my great appreciation to Prof. David Babbel for providing valuable support and giving me constructive advise. Special thanks should be given to teaching assistant for giving me professional guidance about my paper.

\section{References}

[1] Ankel, Sophia. "Coronavirus: Before and after Photos Show Europe Landmarks Empty - Business Insider." Business Insider, Business Insider, 6 Mar. 2020, www.businessinsider.com/coronavirus-before-and-afterphotos-show-europe-landmarks-empty-2020-3.

[2] Brennan, Tom. "Introducing Alibaba's FlyZoo Future..." Alizila.Com, Alizila.com, 10 Mar. 2019, www.alizila.com/introducing-alibabas-flyzoo-future-hotel/.

[3] Frost, Natasha. "The Countries Most Reliant on Tourism for GDP.” Quartz, Quartz, 9 Oct. 2019, qz.com/1724042/thecountries-most-reliant-on-tourism-for-gdp/.

[4] Revfine.com. "Tourism Industry; Everything You Need to Know About Tourism | Revfine.” Revfine.Com, 17 May 2019, www.revfine.com/tourism-industry/\#what-is-the-tourismindustry

[5] "Coronavirus: Preliminary Hotel Performance Impact." STR, str, 2020, str.com/zh-hans/press-release. "Graphics: How Is the Coronavirus Outbreak Reshaping China's Tourism Market?" Cgtn.Com, 2020, news.cgtn.com/news/2020-0417/How-is-the-coronavirus-outbreak-reshaping-China-stourism-market--PLrMJJSbII/index.html.

[6] "Travel \& Tourism: Global Economic Impact 2006-2019 Statista." Statista, Statista, 2019, www.statista.com/statistics/233223/travel-and-tourism--totaleconomic-contribution-worldwide/.

[7] "China Tourism Scenic Spot Association Special Report: Epidemic Situation Impact and Industry Recovery Countermeasures and Suggestions-New Lvjie. Lvjie.Com.Cn, 2020, www.lvjie.com.cn/research/2020/0303/16509.html.

[8] "Epidemic Impact Report: Accommodation industry suffers the most losses Expected to recover in 6 months." Bjd.Com.Cn, 2020 ,

www.bjd.com.cn/a/202003/11/WS5e68d028e4b01e8b91508b 2a.html. 